\title{
Sex determination based on footprint ratio and comparison of toe print pattern in the male and female Nigerian students (A case study of Bowen University students)
}

\author{
Igbinehi Elijah 0 1,5, ${ }^{*}$, Ojo Gideon B 1,2, Thomas Magnus A 1,3,4 and Dawodu Simon E 2 \\ ${ }^{1}$ Department of Anatomy, Faculty of Basic Medical and Health Sciences, Bowen University, Iwo, Nigeria. \\ 2 Department of Medical Biology and Genetics, Near East University, Lefkosa, Cyprus. \\ 3 Department of Anatomy, Lead City University, Ibadan, Nigeria \\ ${ }^{4}$ Department of Anatomy, Atiba University, Oyo, Nigeria \\ 5 Obafemi Awolowo Teaching Hospital Complex, Ile-Ife, Nigeria
}

International Journal of Biological and Pharmaceutical Sciences Archive, 2021, 02(01), 164-175

Publication history: Received on 11 August; revised on 24 September 2021; accepted on 26 September 2021

Article DOI: https://doi.org/10.53771/ijbpsa.2021.2.1.0081

\begin{abstract}
Dermatoglyphics can be described as the study of the patterns of ridges on the skin of the fingers, palms, toes, and soles. These patterns are of interest in anthropology, criminology, and medicine. The skin on the ventral sides of the hands and the plantar sides of the feet is exclusively designed and is corrugated with the ridges and configurations which are functionally useful.

Subjects for the study consisted of 100 persons, 50 males and 50 females, all from Bowen University, Iwo, Osun state of Nigeria and they were all students. The age range was 15-24 years of age. The feature being studied includes the print pattern on their 10 digits and some other parameters to distinguish the sole print patterns of both sexes. The toe print pattern was collected by the use of hand lens, used in viewing the prints on the white paper. For measuring the dimensions of foot prints, the following points were noted;
\end{abstract}

- The maximum length: the distance between the greatest toe and the mid-rear heal point called the pterion.

- The maximum width: the distance between the medial and lateral metatarsal

It was observed that in the male and female population $92 \%$ of the population was found to possess loop patterns on their toes, $4.2 \%$ possessed whorl patterns while 3.8\% possessed arch patterns. Out of the 50 males, $90 \%$ has loop pattern, 3.6\% has whorl pattern, 6.4\% possessed arch pattern in their right foot. 92.4\% has loop patterns, $3.2 \%$ has whorl patterns and $4.4 \%$ has arch pattern in their left foot. In total $91.2 \%$ of the population possessed loop pattern, 3.4 $\%$ possessed whorl pattern while $5.4 \%$ has arch pattern. Considering that of the female population, out of the 50 subjects, $93.2 \%$ possesses loop, $4.4 \%$ has whorl pattern and $2.4 \%$ has arch pattern in their right foot while in the left foot, $92.4 \%$ has loop, $5.6 \%$ has whorl and $2 \%$ has arch patterns in their left foot. In total the female population has 92.8 $\%$ loop, $5 \%$ whorl and just $2.2 \%$ arch patterns.

This results has shown that the female has more whorl pattern (5\%) compared to the female value of $3.4 \%$ of whorl pattern. Also male has higher percentage of arch pattern (5.4\%) compared to the $2.2 \%$ value obtained in females. Sex determination by footprint ratio was carried out and the standard footprint ratio values of 0.371219 and 0.3737645 were obtained. $51 \%$ accuracy was obtained in sex determination using this method. All foot print ratio up to these values and below was predicted female while foot print ratio above these values were predicted male.

\footnotetext{
${ }^{*}$ Corresponding author: Igbinehi Elijah 0

Department of Anatomy, Faculty of Basic Medical and Health Sciences, Bowen University, Iwo, Nigeria. 
Keywords: Standard foot prints ratio; Patterns; Sex determination; Toe print distribution; Dermatoglyphics

\section{Introduction}

Dermatoglyphics is the study of the patterns of ridges on the skin of the fingers, palms, toes, and soles. These patterns are of interest in anthropology, criminology, and medicine. The term dermatoglyphics was coined in 1926 by Dr. Harold Cummins from derma, skin and the Greek glyphe, carve. He later wrote that: "The word is literally descriptive of the delicately sculpted skin surface, inclusive of single ridges and their configural arrangements (Medicinenet, 2012).

The entire human body is clothed with the skin which happens to be the largest and most important organ of the body. It performs many vital functions in the life of an individual, viz. it protects and safe guards the body from the changes of the weather, maintains the body temperature and saves the internal organs of body from the injuries. However, the skin on the ventral sides of the hands and the plantar sides of the feet is exclusively designed and is corrugated with the ridges and configurations which are functionally useful as they help in the grasping without which the objects would easily slip away from the hands. Cummins in 1926 for the first time coined the term 'dermatoglyphics' to this field of science. It has been accepted and adopted internationally. Etymologically, this term is harmonious blend of two words Derma, Skin; Glyphe, Carve. It gives the impression that something has been carved out of the skin (Karthick et al., 2015).

Plantar Dermatoglyphics allow the detective to find the approximate height from footprint and shoe print (Krishan and Sharma, 2007). The Foot tends to be approximately $15 \%$ of the person's average height (Krishan, 2008) Individualistic characteristics of the footprints like numerous creases, flatfoot character, horizontal and vertical ridges, corns, deformities etc. can help the forensic scientist in cases pertaining to criminal identification. In some forensic cases, the need may also arise to estimate body weight from the size of the footprints (Krishan, 2008).

Although the investigation of plantar dermatoglyphics is another interesting study, yet not many investigators have had it done, quite often the prints are incomplete and the exercise has to be repeated. The collection of the toe prints is one of the toughest exercise unlike the finger and palm, the prints of the toes can only be collected on the slips of papers, it is not possible to role the toes like the fingers. One has to be on his toes collect the prints of toes as such a investigation has been made by the braves (Karthick et al., 2015).

These features of dermatoglyphics are formed during the 13th/14th week of the developing embryo and once formed remain permanent and never change throughout the life except in the dimension in commensurate to the growth of an individual. This fact has been tested and confirmed in 1976 at the time when the author was awarded the Senior Fellowship by the Alexender Von Humboldt Foundation, Bonn (Germany) and was engaged in the advance research in the institute of Human Genetics, Medical College. University of Lüebeck, Lüebeck. The most ideal place to scrutinize the age of the appearance of the features of dermatoglyphics was the museum of the institute of Anatomy of the same university where the embryos are preserved in glass jars of different ages of their developments. On critically examination this age of the appearance of the said features was authenticated to be 13th week as stated earlier (Karthick et al., 2015).

\section{Objectives}

The objectives of this study are to

- Enhance our knowledge about the distribution of different print patterns on the toes and also in comparison with the prints on fingers.

- To derive a Standard Footprint Ratio and determine it accuracy in determining sex of individuals in respect to previously existing study (ies)

\subsection{Justification}

The number of analysis done in respect to plantar dermatoglyphics is infinitesimal compared to analysis done on fingerprints. As a matter of fact, no research work has been done on plantar dermatoglyphics using the students of Bowen University Iwo, Osun state-Nigeria as case study.

\subsection{Research Problem}

For years, criminal investigators and forensic scientists have used fingerprints to determine identity. More recently, footprints have been discovered to be an equally reliable identifier. 
Every person's foot has a unique set of ridges that make up a print unmatched by any other human being. As with fingerprints, the footprint's pattern is a unique characteristic that can pinpoint any one particular person. An actual footprint can be checked and matched to an existing print on record, such as one from a birth certificate (Crime Scene, 2015).

Since it has been established that footprints are unique, there is therefore need to evaluate sexual dimorphism in footprints.

\subsection{Expected Contribution to Knowledge}

Today, more emphasis is placed on fingerprint analysis because it has been seen as a worthy means of identification, this project work will help to see if there is any difference in the plantar dermatoglyphics patterns with regards to sexual dimorphism which can be useful in identification. This can also be useful in crime scenes where foot wear are not being worn and also the footprint data can be merged with that which was collected during childbirth.

\section{Limitations}

- Although most of the subjects cooperated, some were skeptical about the process and some even refused to help with the collection of data.

- Due to the method used, patches of stains were left on the subjects foots, which they had to clean on their own so most students decline taking their prints.

- The manual way of data collection was tedious and cumbersome.

- Time was not my friend, during the collection of the data, because the methodology was tedious

\section{Literature review}

In a comparative research carried out by Gottesman, 2012 to compare the relationship between toe prints and fingerprints it was revealed that, the most dominant fingerprints (and toe prints) on the left side are "mirrors" of those on the right side. This research also rejected my initial hypothesis that if the fingerprints of a group of individuals are similar, then there must be a similarity between their toe prints. Rather, the data displayed no strong correlation between an individual's fingerprints and toe prints. This research proves that one cannot predict a fingerprint from a toe print. On the other hand, detectives can conclude that a discovered Ulnar Loop has a high probability of coming from an individual's left side finger or toe. Likewise, if detectives discover a Radial Loop, then it is likely to be from an individual's right side finger or toe.

Kanchan et al. 2012; established that estimation of sex of footprints can help in establishing the biological profile of potential suspects. This research attempts to study the sex differences in the ridge density in four different areas of a footprint. after analysis using standardized techniques; including the upper portion of the medial border of the great toe (F1), the ball of the great toe (F2), the ball of the 5th toe below the triradius point (F3) and the central prominent part of the heel (F4). Male-female differences in footprint ridge density were statistically analyzed for each designated area and compared between right and left sides. The mean footprint ridge density was significantly higher among females than males in all designated areas $(\mathrm{p}<0.05)$ in both feet. No right-left differences were apparent in the analyzed areas. Variations in footprint ridge density between different areas in right and left feet were evident among males and females. This study observes that sex differences exist in footprint ridge density among humans. Maximum sex differences were observed for ridge density in medial ball area, followed by great toe, lateral ball and minimum sex differences were observed in the heel region. It is observed that sex can be estimated from footprint ridge density with reasonable accuracy. The sexing potential of total footprint ridge density was $82.6 \%$ from the right and $83.6 \%$ from the left footprints respectively.

Desai et al. 2013 in their research carried out in Hubli-Dharwar, Karnataka, India, where all the 10 fingerprint patterns were divided into Loops, Whorls and Arches. Results show that Loops are most commonly found fingerprint patterns and Arches are least common. Loops dominated in all the Blood groups of both Rh positive and Rh negative individuals but Whorls were found to be dominating in 0 negative blood group. The only association between gender and finger print patterns in this study is that Loops and Arches were found in higher frequency in Females compared to Males and whorls were found to be high in males compared to females.

Rahman et al. 2014, in their research on sexual dimorphism in footprint, obtained from the staff and undergraduate students of Government Medical College Aurangabad. Maximum Length and Maximum Breadth were calculated. The Footprints Ratio (FPR) for both left and right foot prints of each individual in the study group was calculated separately 
and values obtained were analyzed statistically. Statistical analysis showed that Foot Print Ratio have a significant difference in the mean values for both feet in both sexes. There is a low coefficient of variation. The P values are also are significant. A standard FPR value was derived. Utilizing these values sex determination was done by comparing it with the each of the already calculated FPR values. The percentage accuracy of establishing sex by this method is $80 \%$ which is significant. The Footprints Ratio (FPR) for both left and right foot prints of each individual in the study group was calculated separately and values obtained were analyzed statistically. It was discovered that, sex identity by deriving the Foot Print Ratio FPR is simple, inexpensive and easy to perform, requiring no special training. A Standard Foot Print Ratio (SFPR) for left and right foot prints were derived to be 0.368 and 0.3683 respectively. All FPR values up to these limits predicted as female sex and those values beyond these limits predicted as male sex. The percentage accuracy of establishing sex by this method is $80 \%$ which is significant. It is a reasonably reliable method of sex identification.

Rastogi and Keerthi. 2015, in their research among students of Kasturba Medical College, Mangalore, India. Indicated that each finger print is unique; loops are the most commonly occurring fingerprint pattern while arches are the least common. Males have a higher incidence of whorls and females have a higher incidence of loops. Loops are predominant in blood group $\mathrm{A}, \mathrm{B}, \mathrm{AB}$ and $\mathrm{O}$ in both $\mathrm{Rh}$ positive and $\mathrm{Rh}$ negative individuals except in $\mathrm{O}$ negative where whorls are more common. We can conclude that there is an association between distribution of fingerprint patterns, blood group and gender and thus prediction of gender and blood group of a person is possible based on his fingerprint.

\section{Methodology}

Subjects for the study consisted of 100 persons, 50 males and 50 females, all from Bowen University, Iwo, Osun state of Nigeria and they were all students. The age range was 15-24 years of age. Since the research work is concerning sex, it was essential to have equal number of male and female. The feature being studied includes the print pattern on their 10 digits and some other parameters to distinguish the sole print patterns of both sexes. Each subject was required to fill a questionnaire requesting for the following details:

- Sex Age

- $\quad$ Place of birth Nationality Parents' nationality Interests etc.

Several other parameters were noted in any case of relationship they may have with the variation in toe print patterns, however, along the course of research, some factors were considered irrelevant, or insignificant to the research project.

The following materials were used for this study; 2 round flat bowls, Magnifying lens, Metre rule, Gentian Violet (GV), Methylated spirit, Cotton wool, White drawing paper (Large), Hand Gloves, round sliced foam. The functions of these materials includes

- $\quad$ Round bowls: The foams were placed inside a bowl, while the other bowl was used in washing subjects feet after applying ink.

- $\quad$ Round sliced foam: GV was poured on the film while the foam was placed inside the bowl

- Magnifying lens: This was used in the course of analysis

- Methylated spirit: This was used to clean off the GV off the subject's foot

- Cotton wool : This was used along with the methylated spirit to clean off the GV

- White drawing paper: The subject, stained with GV, was stamped on the neat, white paper

- Hand Gloves: This was used to protect my hand from germs and stains while cleaning the subjects feet

- $\quad$ Metre rule : This was also used in the course of the analysis

The method for recording the footprint from subjects was a crude method, equipment or a tool used mainly for this purpose could not be found but improvisation was carried out.

The subjects' feet were cleaned with methylated spirit to have any particles or debris that may affect the imprinting. A slice of foam is inserted into a flat bowl while the GV ink is poured inside it and it is spread so as to be contained in all part of the foam .The subjects' foot is inserted into the bowl one at a time and asked to stand on the leg so that the ink would cover the sole of the foot and more sufficiently. The stained foot is the placed on white large paper and the print is recorded. The stained feet are cleansed with Methylated spirit. Most of the times the ink stain is not removed completely and the subject is advised to take his or her bath and then the ink would be gone permanently. While all these are being done, the subject is given a questionnaire to fill containing the data of the subject like the age, place of birth and nationality. 
The toe print pattern was collected by the use of hand lens, whether it is a loop, whorl or an arch pattern. The patterns were used as similar to that of fingerprint seen in previous research work, where the toe prints patterns was compared to that of finger print, using the same conventional type of patterns (loop, arch and whorl). (Sidhart et al., 2014)

For measuring the dimensions of foot prints, the following points were noted

- The maximum length: the distance between the greatest toe and the mid-rear heal point called the pterion

- The maximum width: the distance between the medial and lateral metatarsal The values were recorded and tabulated as shown in the result

for the purpose of analysis descriptive statistics was employed, the number of different patterns was noted and illustrated with a pie chart, while the foot print ratio was done and the mean and standard deviation was done, all these was done by a software called Microsoft Excel (2010). The formula for the footprint ratio is taken as;

$$
=\frac{\text { Maximum width of the footprint }}{\text { Maximum length of the footprint }} \ldots . . . . . .(\text { Rahman, 2014). }
$$

\section{Results}

A total of 100 students participated in the research study with the aid of an anonymous questionnaire, which supplied data such as tribe of both parents and their nationality. In total, there were 1000 digits, a total of 50 male and 50 female.

\subsection{Distribution of Toe Prints Pattern In The Population Of Study}

The total of a hundred subjects involved in this study, in which ten digits including left and right digits includes (Table 1):

Table 1 Percentage values of the toe print distribution in the pattern of study

\begin{tabular}{|l|c|c|c|}
\hline \multicolumn{2}{|c|}{ Percentage values of toe print distribution in the population } \\
\hline $\begin{array}{c}\text { Type of toe print } \\
\text { pattern }\end{array}$ & \% Value in right toe & \% Value in left toe & $\begin{array}{c}\text { \% Value of pattern type in male } \\
\text { population }\end{array}$ \\
\hline Loop pattern & 90 & 92.4 & 91.2 \\
\hline Whorl pattern & 3.6 & 3.2 & 5.4 \\
\hline Arch pattern & 6.4 & 4.4 & \% Value of pattern type in female \\
type
\end{tabular}




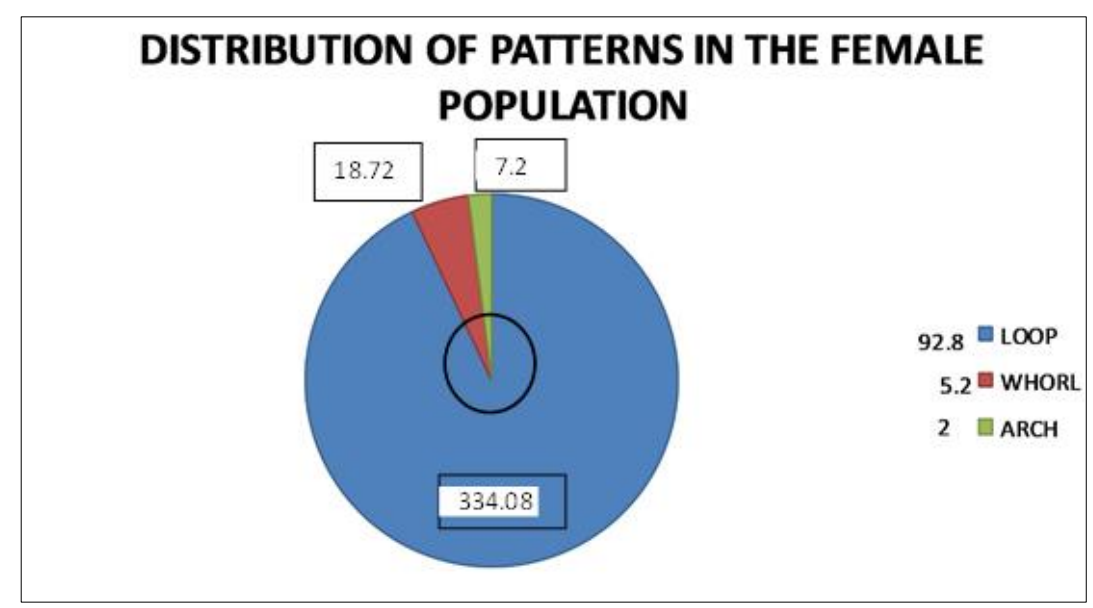

Figure 1 Toe Print Pattern Distribution in Female Population

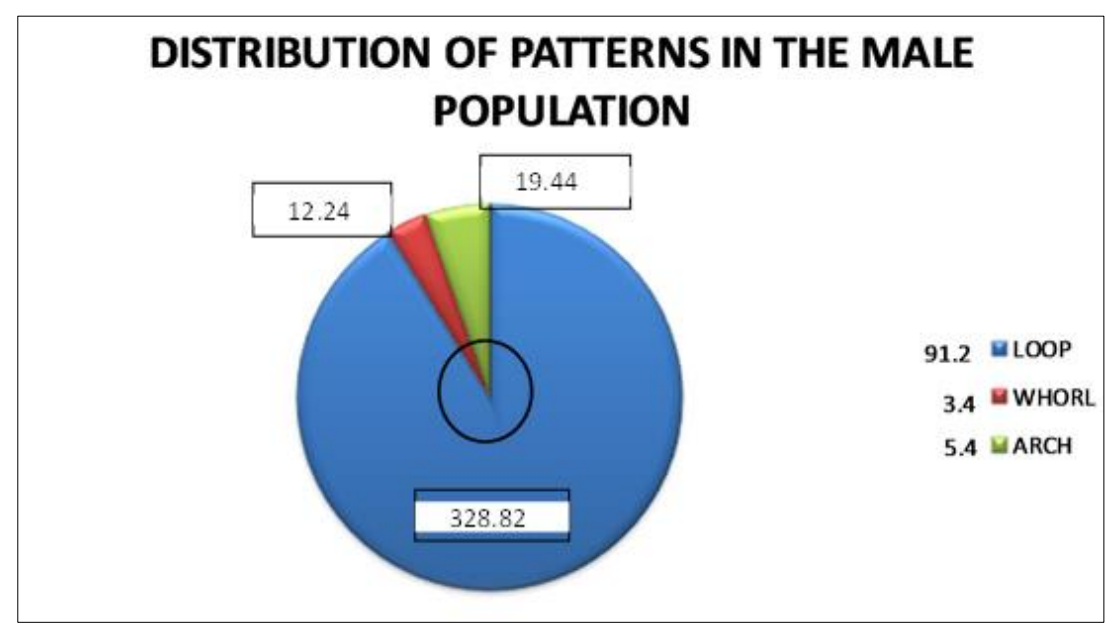

Figure 2 Toe Print Pattern Distribution in Male Population

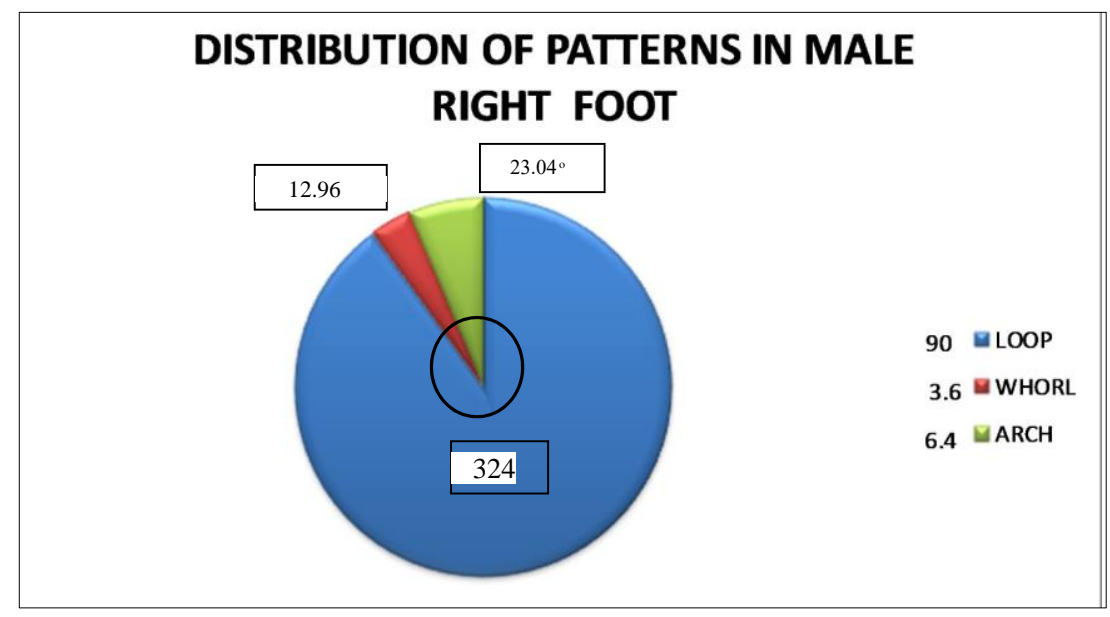

Figure 3 Toe Print Pattern in the Right Foot of Male Population 


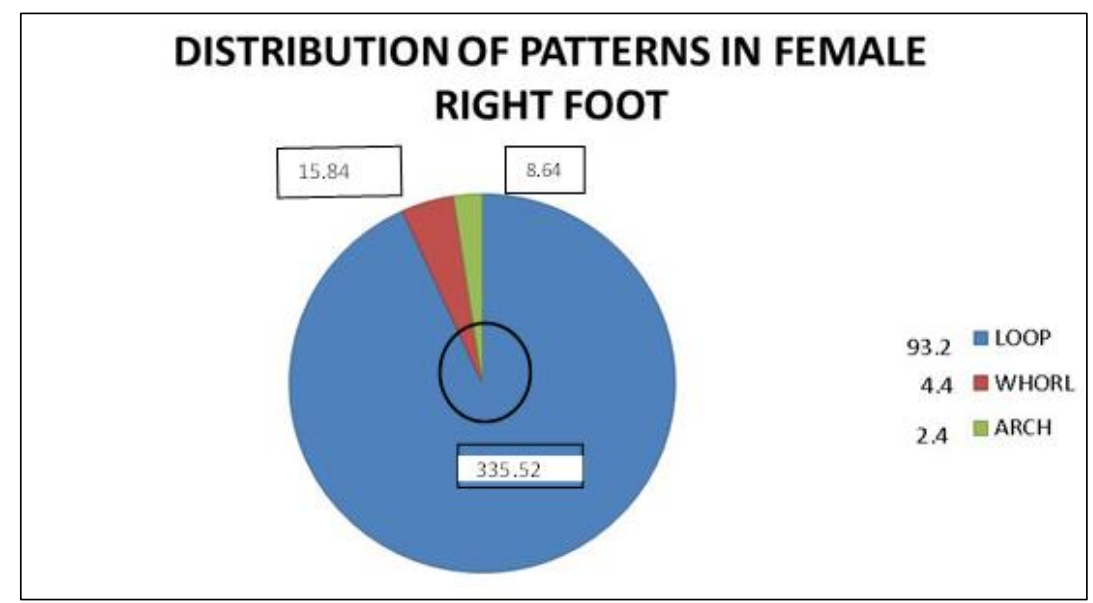

Figure 4 Toe Print Pattern in the Right Foot of Female Population

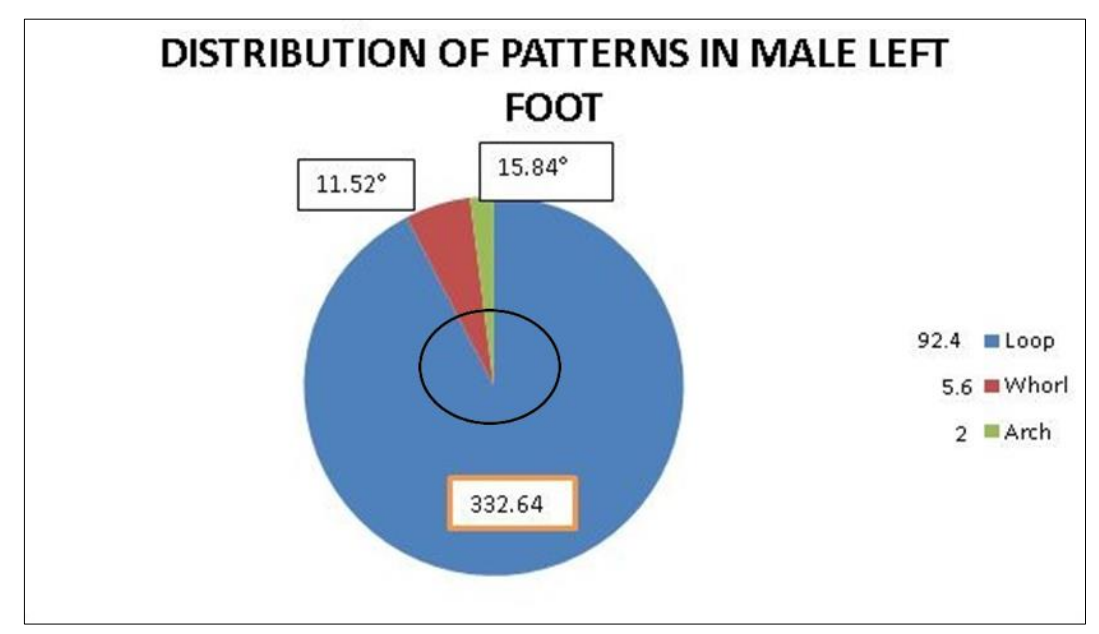

Figure 5 Toe Print Pattern in the Left Foot of Male Population

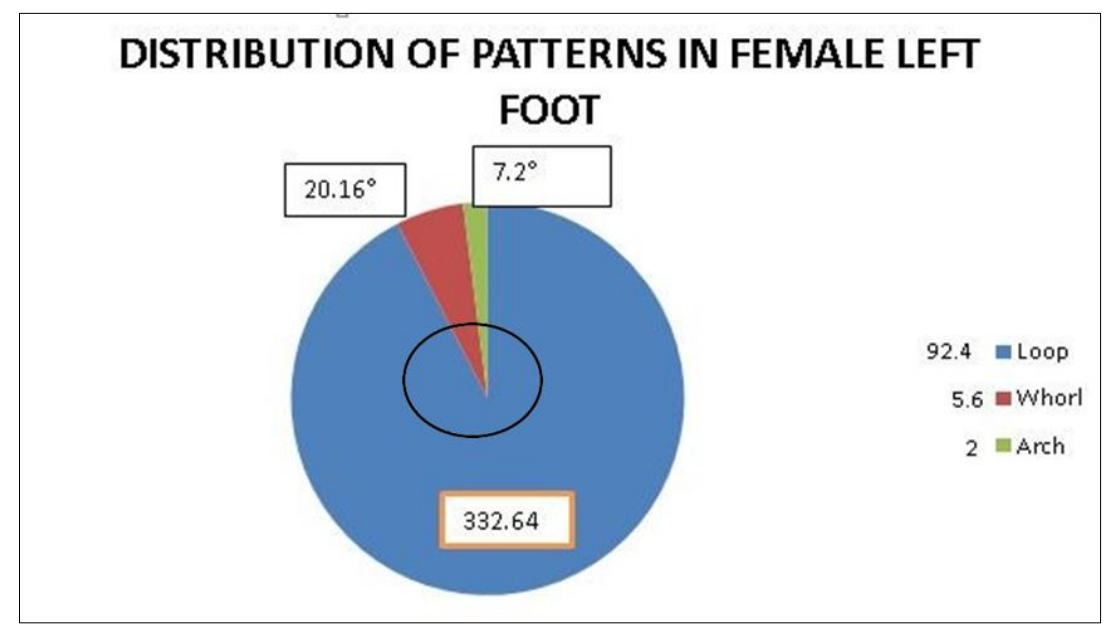

Figure 6 Toe Print Pattern in the Left Foot of Female Population 


\subsection{Sexual Dimorphism in Toe Print Ratio}

The toe print ratio for both left and right toe prints of each individual in the study group was calculated separately and values were obtained and analyzed statistically in a computer by the use of a statistical software package called Microsoft Excel (2010). Summary of these values were obtained and tabulated in table 2. From Table 2, it follows that the toe print ratio has a significant difference in mean value for both male and female sexes, and also the standard deviation was obtained.

Table 2 Toe print ratio of individual foot

\begin{tabular}{|c|c|c|c|c|}
\hline \multirow[t]{2}{*}{ Sr. no. } & \multicolumn{2}{|c|}{ Male } & \multicolumn{2}{|c|}{ Female } \\
\hline & Left & Right & Left & Right \\
\hline \multirow[t]{2}{*}{1} & 0.3517 & 0.3472 & 0.3437 & 0.3306 \\
\hline & 79 & 22 & 5 & 45 \\
\hline \multirow[t]{2}{*}{2} & 0.3728 & 0.3733 & 0.3797 & 0.3931 \\
\hline & 81 & 91 & 47 & 62 \\
\hline \multirow[t]{2}{*}{3} & 0.3339 & 0.3524 & 0.3617 & 0.3662 \\
\hline & 69 & 9 & 89 & 55 \\
\hline \multirow[t]{2}{*}{4} & 0.3862 & 0.3787 & 0.3599 & 0.3760 \\
\hline & 75 & 88 & 14 & 68 \\
\hline \multirow[t]{2}{*}{5} & 0.3531 & 0.3584 & 0.3808 & 0.3744 \\
\hline & 6 & 91 & 51 & 77 \\
\hline \multirow[t]{2}{*}{6} & 0.3815 & 0.3774 & 0.3668 & 0.3739 \\
\hline & 26 & 32 & 12 & 13 \\
\hline \multirow[t]{2}{*}{7} & 0.3505 & 0.3675 & 0.3702 & 0.3489 \\
\hline & 54 & 37 & 13 & 36 \\
\hline \multirow[t]{2}{*}{8} & 0.3488 & 0.3416 & 0.3464 & 0.3501 \\
\hline & 37 & 03 & 38 & 95 \\
\hline \multirow[t]{2}{*}{9} & 0.3519 & 0.3500 & 0.4104 & 0.3884 \\
\hline & 55 & 93 & 17 & 3 \\
\hline \multirow[t]{2}{*}{10} & 0.3650 & 0.3504 & 0.3983 & 0.4067 \\
\hline & 19 & 66 & 05 & 8 \\
\hline \multirow[t]{2}{*}{11} & 0.3706 & 0.3913 & 0.3949 & 0.4224 \\
\hline & 9 & 4 & 58 & 14 \\
\hline \multirow[t]{2}{*}{12} & 0.3730 & 0.3471 & 0.3441 & 0.3515 \\
\hline & 77 & 7 & 3 & 15 \\
\hline \multirow[t]{2}{*}{13} & 0.3568 & 0.3529 & 0.3532 & 0.3728 \\
\hline & 63 & 41 & 01 & 07 \\
\hline \multirow[t]{2}{*}{14} & 0.3345 & 0.3533 & 0.3852 & 0.3679 \\
\hline & 72 & 83 & 81 & 65 \\
\hline \multirow[t]{2}{*}{15} & 0.3472 & 0.3651 & 0.3905 & 0.3846 \\
\hline & 22 & 08 & 58 & 15 \\
\hline \multirow[t]{2}{*}{16} & 0.3670 & 0.3655 & 0.3673 & 0.3547 \\
\hline & 89 & 46 & 47 & 72 \\
\hline \multirow[t]{2}{*}{17} & 0.4034 & 0.3803 & 0.3707 & 0.3574 \\
\hline & 71 & 42 & 63 & 47 \\
\hline \multirow[t]{2}{*}{18} & 0.3891 & 0.4008 & 0.3911 & 0.3777 \\
\hline & 21 & 44 & 11 & 78 \\
\hline \multirow[t]{2}{*}{19} & 0.3809 & 0.3632 & 0.3551 & 0.3663 \\
\hline & 52 & 48 & 8 & 79 \\
\hline 20 & 0.3784 & 0.4032 & 0.3974 & 0.4047 \\
\hline
\end{tabular}


International Journal of Biological and Pharmaceutical Sciences Archive, 2021, 02(01), 164-175

\begin{tabular}{|c|c|c|c|c|}
\hline & 86 & 26 & 36 & 62 \\
\hline \multirow[t]{2}{*}{21} & 0.3732 & 0.3732 & 0.3433 & 0.35 \\
\hline & 39 & 39 & 96 & \\
\hline \multirow[t]{2}{*}{22} & 0.4 & 0.3574 & 0.3687 & 0.4083 \\
\hline & & 07 & 37 & 33 \\
\hline \multirow[t]{2}{*}{23} & 0.3409 & 0.3449 & 0.2913 & 0.3473 \\
\hline & 96 & 61 & 67 & 45 \\
\hline \multirow[t]{2}{*}{24} & 0.3950 & 0.4023 & 0.3606 & 0.34 \\
\hline & 62 & 9 & 56 & \\
\hline \multirow[t]{2}{*}{25} & 0.3584 & 0.3667 & 0.3417 & 0.3389 \\
\hline & 91 & 95 & 72 & 83 \\
\hline \multirow[t]{2}{*}{26} & 0.3553 & 0.3626 & 0.3454 & 0.3644 \\
\hline & 11 & 37 & 55 & 44 \\
\hline \multirow[t]{2}{*}{27} & 0.3591 & 0.3775 & 0.3718 & 0.3809 \\
\hline & 84 & 93 & 81 & 52 \\
\hline \multirow[t]{2}{*}{28} & 0.3671 & 0.382 & 0.3658 & 0.3811 \\
\hline & 88 & & 54 & 48 \\
\hline \multirow[t]{2}{*}{29} & 0.3846 & 0.3774 & 0.3641 & 0.3622 \\
\hline & 15 & 32 & 73 & 05 \\
\hline \multirow[t]{2}{*}{30} & 0.375 & 0.3922 & 0.3661 & 0.3488 \\
\hline & & 26 & 42 & 37 \\
\hline \multirow{2}{*}{31} & 0.3891 & 0.3644 & 0.3557 & 0.3830 \\
\hline & 4 & 44 & 31 & 65 \\
\hline \multirow[t]{2}{*}{32} & 0.3505 & 0.3495 & 0.3501 & 0.3888 \\
\hline & 15 & 93 & 09 & 89 \\
\hline \multirow[t]{2}{*}{33} & 0.3370 & 0.3370 & 0.3682 & 0.3666 \\
\hline & 79 & 79 & 01 & 67 \\
\hline \multirow[t]{2}{*}{32} & 0.3582 & 0.3506 & 0.3195 & 0.3140 \\
\hline & 76 & 94 & 02 & 5 \\
\hline \multirow[t]{2}{*}{35} & 0.3857 & 0.4016 & 0.3975 & 0.3650 \\
\hline & 14 & 74 & 66 & 19 \\
\hline \multirow[t]{2}{*}{36} & 0.343 & 0.3382 & 0.4259 & 0.4225 \\
\hline & 96 & 9 & 26 & 35 \\
\hline \multirow[t]{2}{*}{37} & 0.3830 & 0.4081 & 0.3628 & 0.3571 \\
\hline & 65 & 63 & 32 & 43 \\
\hline \multirow[t]{2}{*}{38} & 0.3437 & 0.3715 & 0.3668 & 0.3711 \\
\hline & 5 & 42 & 12 & 79 \\
\hline \multirow[t]{2}{*}{39} & 0.3665 & 0.3833 & 0.4317 & 0.3551 \\
\hline & 34 & 33 & 18 & 02 \\
\hline \multirow[t]{2}{*}{40} & 0.3616 & 0.3740 & 0.4042 & 0.3931 \\
\hline & 24 & 74 & 55 & 62 \\
\hline \multirow[t]{2}{*}{41} & 0.3511 & 0.3893 & 0.3673 & 0.3917 \\
\hline & 45 & 13 & 47 & 53 \\
\hline \multirow[t]{2}{*}{42} & 0.3629 & 0.3690 & 0.3956 & 0.4241 \\
\hline & 03 & 48 & 52 & 07 \\
\hline \multirow[t]{2}{*}{43} & 0.3461 & 0.38 & 0.3903 & 0.3547 \\
\hline & 54 & & 51 & 01 \\
\hline 44 & 0.3811 & 0.3688 & 0.3395 & 0.3483 \\
\hline
\end{tabular}




\begin{tabular}{|c|l|l|l|l|}
\hline & 48 & 52 & 45 & 61 \\
\hline \multirow{2}{*}{45} & 0.3696 & 0.3937 & 0.3544 & 0.3586 \\
\cline { 2 - 5 } & 5 & 01 & 3 & 5 \\
\hline \multirow{2}{*}{46} & 0.3522 & 0.3700 & 0.3779 & 0.408 \\
\cline { 2 - 5 } & 73 & 79 & 53 & \\
\hline \multirow{2}{*}{47} & 0.3822 & 0.4015 & 0.3849 & 0.3717 \\
\cline { 2 - 5 } & 39 & 75 & 06 & 47 \\
\hline \multirow{2}{*}{48} & 0.3692 & 0.3636 & 0.3800 & 0.3936 \\
\cline { 2 - 5 } & 95 & 36 & 9 & 65 \\
\hline 49 & 0.3492 & 0.3719 & 0.3346 & 0.3441 \\
\hline \multirow{3}{*}{50} & 06 & 01 & 38 & 3 \\
\cline { 2 - 5 } & 0.3893 & 0.3893 & 0.3422 & 0.3455 \\
\hline \multirow{2}{*}{ MEAN } & 0.3655 & 0.3706 & 0.3687 & 0.3709 \\
\cline { 2 - 5 } & 8 & 72 & 49 & 8 \\
\hline \multirow{2}{*}{ ST DV } & 0.0177 & 0.0187 & 0.0258 & 0.0245 \\
\cline { 2 - 5 } & 78 & 03 & 87 & 58 \\
\hline
\end{tabular}

A standard FPR value was derived at first for each of the left and right toe print separately using a scheme: STANDARD FOOT PRINT RATIO (SFPR)

$$
\frac{(\text { Male mean FPR }- \text { SDV })+(\text { Female mean FPR }+ \text { STDV })}{2}
$$

Standard values thus calculated are tabulated in table 3

Table 3 Standard toe print Ratio (SFPR) Values

\begin{tabular}{|l|l|}
\hline Toe print (toe) & SFPR Value \\
\hline Right & 0.371219 \\
\hline Left & 0.3737645 \\
\hline
\end{tabular}

Using these values sex determination was done by comparing it with the each of the already calculated FPR values from each participant in following order.

Every FPR value of Right and Left toe Prints up to the limits of the SFPR values 0.371219 and 0.3737645 respectively (Table 3) were reported as Female sex while those values above these limits reported as male sex. Percentage accuracy of reporting of sex identity by this method is then checked in the data record sheet as the sex of each participant is known and entered in it (Table 4). About 51\% accuracy was found in this result.

Table 4 Percentage Accuracy of Reported Sex Identity

\begin{tabular}{|c|l|c|c|c|}
\hline Sex & Side & $\begin{array}{c}\text { Number of prints } \\
\text { studied }\end{array}$ & $\begin{array}{c}\text { Number of prints sex reported } \\
\text { correctly }\end{array}$ & $\begin{array}{c}\text { Percent } \\
\text { incidence }\end{array}$ \\
\hline male & right & 50 & 24 & 48 \\
\hline & left & 50 & 18 & 36 \\
\hline female & right & 50 & 29 & 58 \\
\hline & left & 50 & 31 & 62 \\
\hline
\end{tabular}




\section{Discussion}

In the course of this project work, two studies were carried out, the first was the comparison of the distribution of the different patterns among toes in both sexes, the second being the determination of sex by toe print ratio.

It was observed that in the male and female population $92 \%$ of the population was found to possess loop patterns on their toes, $4.2 \%$ possessed whorl patterns while 3.8\% possessed arch patterns. Out of the 50 males, $90 \%$ has loop pattern, $3.6 \%$ has whorl pattern, 6.4\% possessed arch pattern in their right foot. $92.4 \%$ has loop patterns, $3.2 \%$ has whorl patterns and $4.4 \%$ has arch pattern in their left foot. In total $91.2 \%$ of the population possessed loop pattern, 3.4 $\%$ possessed whorl pattern while $5.4 \%$ has arch pattern. Considering that of the female population, out of 50 subjects too, $93.2 \%$ possesses loop, $4.4 \%$ has whorl pattern and $2.4 \%$ has loop pattern in their right foot while in the left foot, $92.4 \%$ has loop, $5.6 \%$ has whorl and $2 \%$ has arch patterns in their left foot. In total the female population has $92.8 \%$ has loop, 5\% has whorl and just $2.2 \%$ has arch patterns. This results has shown that there female has more whorl pattern (5\%) compared to the female value of 3.4\% of whorl pattern. Also male has higher percentage of arch pattern (5.4\%) compared to the $2.2 \%$ value obtained in females. Comparing the results gotten from the previous ones, there has not been any direct research that compared the differences in the toe print patterns across sexes.

In respect to toe print ratio, it was observed that the values estimated from this research work gotten is different when compared to the values estimated from previous research work. (Rahman et al, 2014). This research work has shown that there cannot be a specific range of toe print ratio values to predict sex, because the parameters which make up the toe print ratio (length and width of toe) may differ from place to place due to different factors like diet, race, geographical location etc.

Comparing the frequency of the patterns gotten from the prints to a previous work on finger prints, it was deduced from the previous study that loop pattern has the highest frequency $(51.1 \%)$ followed by whorl pattern $(36.8 \%)$. Arch pattern is the rarest pattern (7.8\%). There is more predominance of loop and whorl pattern than average values in this study, in this research work, it was observed that $92.8 \%$ of the population possessed loop pattern, $5 \%$ possessed whorl patterns on their toes, while the least possessed pattern was the arch pattern, which was $2.2 \%$ of the total pattern population. This study shows that while whorl patterns and arch patterns may also be predominant in the fingers of the hand, it is greatly reduced in the toes, which possessed majorly loop patterns of prints, while there is more predominance of arch and loop pattern than average values in that of the finger, it was predominantly loop patterns in that of the toes.

Sex determination by footprint ratio was carried out and the standard footprint ratio values of 0.371219 and 0.3737645 were obtained, 51\% accuracy was obtained in sex determination using this method. All foot print ratio up to these values and below was predicted, female while foot print ratio above these values were predicted male. This work was done based on some pre-existing work on sex determination by footprint ratio (Rahman et al, 2014).

\section{Recommendations}

Our recommendation concerning the use of footprint ratio in determining sex is the use of many subjects during the research work.

\section{Conclusions}

From this research work we noted that it's not something realistic to obtain a universal "Standard Footprint Ratio", because the footprint ratio is derived from the length and breadth of the foot which can vary due to different factors, making it a herculean task to get a value which can be used to determine sex universally, but there is a possibility of getting values for specific regions or areas.

\section{Compliance with ethical standards}

\section{Acknowledgments}

The authors appreciate the immense contributions of Mr M. A Adeniyi and Mr Adesina Adeniyi both formerly in the Laboratory Unit of the Department of Anatomy, Faculty of Basic Medical and Health Sciences, Bowen University, Iwo, Nigeria 


\section{Disclosure of conflict of interest}

The authors declared that there are no conflicts of interest in this research work.

\section{Statement of ethical approval}

This research work was conducted in compliance with ethical standard because clearance was obtained from the ethical committee of the College of Health Sciences, Bowen University, Iwo, Nigeria.

\section{Statement of informed consent}

informed consent will be obtained from the study population.

\section{References}

[1] Ashbaugh R David. Ridgeology Modern Evaluative Friction Ridge Identification. 2015.

[2] Boundless. Arches of the Foot: Boundless Anatomy and Physiology. 2015.

[3] Crime Scene: www.crimescene-forensics.com/Fingerprints.html, Retrieved May 18, 2015. Cummins H. and Midlo C. (1926): Palmar and plantar epidermal ridge configurations in European Americans. Am. J. Phys. Anthrop. 2015; 9: 471-502.

[4] Daniela H. Gottesman. Exploring the Relationship among Fingerprints and Toeprints. Carlifornia State Science Fair. 2015.

[5] Desai Bhavana, Jaiswal Ruchi, Tiwari Prakash, Kalyan JL. Study of Fingerprints patterns in Relationship with Blood group and Gender Statistical .Research Journal of Forensic Sciences. 2013; 1(1): 15- .

[6] Durham NM, Plato CC. Trends in Dermatoglyphic Research,Springer Science \& Business Media. 1990.

[7] Kanchan T, Krishan K, Aparna K, Shyamsunder S. Footprint ridge density: a new attribute for sexual dimorphism. 2012.

[8] Keith M, Athur D, Anne A. Clinically Oriented Anatomy, 7th Edition. Pps 609-614, Lippincott Williams \& Wilkins, a Wolters Kluwer Business. 2014.

[9] Krishan K. Determination Of stature From Foot and its segment in a north Indian population. American Journal of Forensic Medical Pathology 2008.Vol. 29 Issue 4 pp 297-303

[10] Krishan K. Establishing correlation of footprints with body weight-forensic aspects". Forensic Sci. Int. 2008; 179(1): 63-9.

[11] Krishan K, Sharma A. Estimation of stature from dimensions of hands and feet in a North Indian population". J Forensic Leg Med. 2007; 14(6): 327-32.

[12] Karthick, Masthan K. M .K, Babu N. A, Krupaa R. J, Anitha N. Dermatoglyphics -A Review. Biomed Pharmacol J 2015;8(October Spl Edition)

[13] Rahman MA, Mahajan AA, Shroff AG. Sexual Dimorphism in Foot Print Ratio. 2014.

[14] Medicinenet. www.medicinenet.com. 2012 Retrieved April 2015.

[15] Mescher, L Anthony. Junqueira's Basic Histology, Chapter 18,12th Edition. Prateek, Rastogi and Keerthi, R Pillai (2013): A study of fingerprints in relation to gender and blood group, J Indian Acad Forensic Med. 2010; 32(1).

[16] Sidhart Timsina, Kar SM, Madan Prasad Baral. A comparative sex wise study of fingerprints in relation to toe prints; International Journal of Recent Trends in Science and Technology. 2014; 12(1): 164-167.

[17] Yogesh N Umraniya, Hetal H Modi, Himanshu K Prajapati. Sexual Dimorphism In Dermatoglyphics Pattern Study. International Journal of Medical And Public Health Science Research. 2013; 1(2): 1-6. 